\title{
A meta-analysis of genotype $\times$ environment interaction on sugar beet performance
}

\author{
Parviz Fasahat $^{1}$, Mohsen Aghaeezadeh ${ }^{1}$, Mozhdeh Kakueinezhad ${ }^{1}$, \\ Leila Jabbari ${ }^{2}$
}

\author{
${ }^{1}$ Sugar Beet Seed Institute (SBSI), Agricultural Research, Education and Extension Organization \\ (AREEO), Karaj, Iran, e-mail: parviz.fasahat@gmail.com \\ ${ }^{2}$ Agricultural Biotechnology Research Institute of Iran, Agricultural Research, Education and \\ Extension Organization (AREEO), Karaj, Iran
}

\begin{abstract}
SUMMARY
The evaluation of sugar beet genotypes under different climate conditions is a principal goal of breeding programs. In most studies, environment has a high influence on the qualitative and quantitative traits of sugar beet. Therefore, data collected from different environments may contribute to more accurate genotype selection. In this study, the effect of different environments on sugar beet genotypes' performance was evaluated using a meta-analysis method based on Hedges' technique. Data were collected from 149 trials conducted in twelve regions in Iran over 15 years (2003-18). For all trials, the value of the traits was weighted, and subsequently the effect size, reaction ratio and confidence interval were estimated. Among the studied environments, Khoy had a positive effect on root yield, sugar content, sugar yield and white sugar yield. As could be expected, the effect of environment on final yield formation was high, so that the Shiraz environment had a negative effect on root yield and sugar yield. Overall, the ranking of environments based on the meta-analysis results was quite different from that obtained by comparison of mean results.
\end{abstract}

Key words: environment, genotype, meta-analysis, quality, sugar beet, yield

\section{Introduction}

Crop yields can be improved through genetic enhancement of potential yields as well as the elimination of barriers that prevent cultivars from reaching their potential yield. The latter can be removed mainly through cultivar breeding for resistance to pests and stress, performance of agronomic operations, and agricultural input application. However, as inputs increase, the gap between 
actual yield and potential yield decreases, though for economic agricultural systems based on lower inputs and energy consumption, performance should be achieved mainly through breeding, rather than by using more agronomic technologies-especially in areas less suited to cultivation and associated with high production costs.

Sugar beet is one of the main sources of sugar production, and is cultivated in most parts of Iran. Sugar is a strong and very energetic dietary substance, so that only 25 grams of sugar is enough to produce 100 calories (https://www.heart.org/en/healthy-living/healthy-eating/eat-smart/sugar/sugar101). The sucrose content in sugar beet has increased from $6 \%$ (fresh weight) in the initial selection to $18 \%$ (fresh weight) in today's hybrids (Fasahat et al., 2018). From the agronomic perspective, the main objective of sugar beet breeding is to improve sugar yield, which is the result of root yield multiplied by sucrose content. Most of the commercially produced sugar beet cultivars are hybrids, made possible by the discovery of cytoplasmic male-sterility (Owen, 1945), which allows the development of male-sterile parental lines. Typically, a cytoplasmic male-sterile line is crossed with a maintainer (O-type) line to develop a male-sterile F1 generation. Then, F1 progenies are used as maternal parent in a cross with pollinator lines. Considering the differences within a country among different regions and years in terms of soil and climate conditions, it is necessary to study cultivars' response to different regions and over several years to be able to evaluate their performance.

Every year, various studies are carried out on different aspects of field crops. Owing to the influence of various factors, the results of these studies are not the same and sometimes contradictory. For example, results obtained from studies on the effect of seed size on seedling emergence rate are different: some indicate a positive effect, some negative, and others have reported no effect (Soltani and Soltani, 2015). In such circumstances, drawing a final conclusion is difficult. Meta-analysis has been developed for such a situation. With the help of this method, various studies on a particular topic are analyzed statistically, and reliable conclusions are drawn from numerous dispersed and even contradictory 
studies. Huang et al. (2013) evaluated the effect of plant residues on rice yield in China using meta-analysis. In their study, all papers published before 2013 were reviewed and the collected data were divided into two groups; the first group included studies that used equal amounts of inorganic fertilizers with or without plant residues, and the second group consisted of studies which compared plant residue application plus low inorganic fertilizers with sole application of inorganic fertilizers. In the first group, data were used to investigate the effect of plant residues on rice yield and its effective factors, and in the second group the effect of the amount of plant residue fertilizer on rice production was evaluated. In general, a significant increase (about 5.2\%) in rice yield was observed using plant residues. The number of panicles as well as the percentage of filled grains also increased, but this increase was not significant. Barker et al. (2019) used a meta-analysis method to examine 352 sets of genotype, environment, and genotype $\times$ environment interaction estimates collected from 72 studies of Salicaceae, to compare the effects of these sources of variation across plant traits. The results showed that variation in defense compounds and insect herbivore activity levels was mainly influenced by genetic factors, while variation in plant growth and foliar nitrogen was more environmentally determined. In addition, plant growth, foliar nitrogen levels and insect herbivore activity differed across different environments (year $\times$ location).

The Sugar Beet Seed Institute is working on the breeding and development of sugar beet cultivars. Every year, new varieties are evaluated in different regions across the country to evaluate their performance under different environmental conditions. In this study, the results of field trials conducted in different regions over 15 years were summarized to evaluate the effect of different environments on sugar beet performance via a meta-analysis method.

\section{Materials and methods}

\subsection{Data collection}

Data were collected from 153 trials conducted in 15 regions in Iran over 15 years 
(2003-18). Three regions (Ardabil, Borujerd, and Shahrud) were excluded, as data from only a one-year trial were available. Consequently, 149 trials performed in twelve regions were considered for this study (Appendix). General characteristics of the trial regions, such as longitude/latitude, are presented in Table 1.

Table 1. Characteristics of the trial regions

\begin{tabular}{clrcc}
\hline No. & \multicolumn{1}{c}{ City } & Longitude & Latitude & Sea level $(\mathrm{m})$ \\
\hline 1 & Karaj & $50^{\circ} 75^{\prime}$ & $35^{\circ} 59^{\prime}$ & 1300 \\
2 & Mashhad & $59^{\circ} 39^{\prime}$ & $36^{\circ} 12^{\prime}$ & 998 \\
3 & Shiraz & $52^{\circ} 42^{\prime}$ & $29^{\circ} 46^{\prime}$ & 1598 \\
4 & Miandoab & $46^{\circ} 06^{\prime}$ & $36^{\circ} 57^{\prime}$ & 1294 \\
5 & Isfahan & $51^{\circ} 40^{\prime}$ & $32^{\circ} 37^{\prime}$ & 1550 \\
6 & Kermanshah & $46^{\circ} 48^{\prime}$ & $24^{\circ} 16^{\prime}$ & 1365 \\
7 & Kerman & $56^{\circ} 58^{\prime}$ & $30^{\circ} 15^{\prime}$ & 1753 \\
8 & Hamedan & $48^{\circ} 30^{\prime}$ & $34^{\circ} 47^{\prime}$ & 1819 \\
9 & Oroumieh & $44^{\circ} 58^{\prime}$ & $37^{\circ} 34^{\prime}$ & 1332 \\
10 & Moghan & $47^{\circ} 55^{\prime}$ & $39^{\circ} 39^{\prime}$ & 32 \\
11 & Khoy & $44^{\circ} 56^{\prime}$ & $38^{\circ} 32^{\prime}$ & 1147 \\
12 & Meshginshahr & $47^{\circ} 40^{\prime}$ & $38^{\circ} 23^{\prime}$ & 1394 \\
\hline
\end{tabular}

The average temperatures and precipitations of the environments within the studied period are presented in Figures 1 and 2 respectively. Classification of the regions in terms of climatic similarity and selection of the reference station is as follows: Mashhad represents a temperate region, Shiraz a semi-warm climate, Miandoab a semi-cold climate, Hamedan a cold climate, Karaj cold semi-arid, Kermanshah warm and temperate, Isfahan cold semi-arid, Oroumieh warm and temperate, Khoy cold semi-arid, Meshginshahr warm and temperate, Kerman a warm and dry climate; Moghan was designated as a particular climate (Research Performance Report of SBSI, 2018). These regions are recognized as the main areas of sugar beet cultivation, and can therefore be considered as representative for a wide range of environmental conditions.

All regions applied uniform management protocols, and plots were replicated in standard statistical field designs. The main requirement for data collection was that the information regarding mean values and the number of replicates for the selected characteristics, such as root yield, sugar yield, sugar content, white sugar 
A meta-analysis of genotype $\times$ environment interaction on sugar beet performance 225

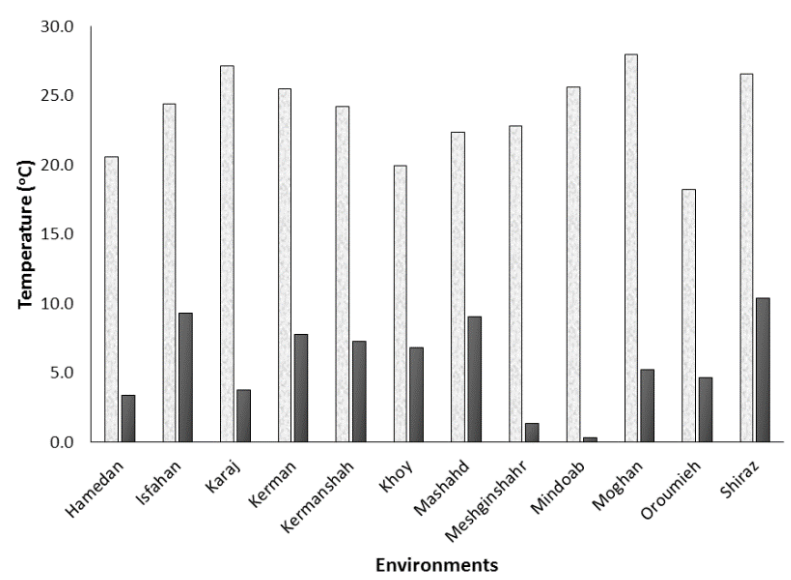

Figure 1. Average minimum and maximum temperature of the environments within the studied period; dark columns show the minimum and light columns show the maximum temperature

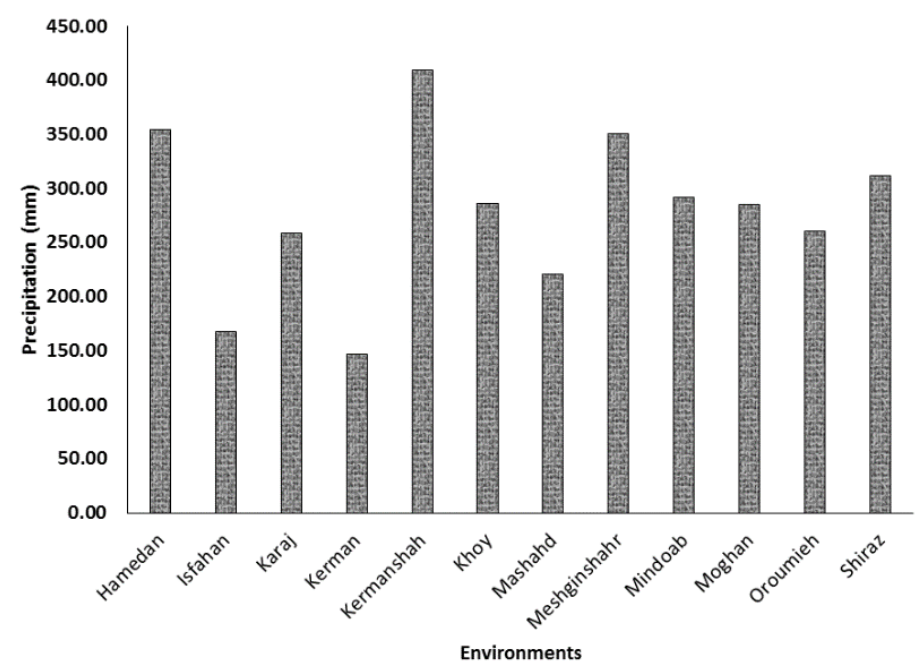

Figure 2. Average precipitation ( $\mathrm{mm}$ ) of the environments within the studied period

yield, sugar extraction coefficient, as well as impurities, was reported for each trial. Roots harvested from uniform tests were analyzed for qualitative traits at the Sugar Technology laboratory at SBSI in Karaj, Alborz, Iran. 


\subsection{Meta-analysis}

The meta-analysis method based on Hedges' (1992) technique was used in this study. In this method, not only the differences between studies, but also the variance of the effect size will be considered. Therefore, in each study, the mean values, standard deviation, and sample size (number of replicates in each trial) were extracted for both control and genotypes. Then the reaction ratio $\mathrm{R}$ was calculated (Hedges et al., 1999) followed by the logarithm of the reaction ratio (1)

$$
R=\frac{\overline{X E}}{\overline{X C}}
$$

where $\overline{X E}$ is the mean value of the trait and $\bar{X} C$ is the mean value of the control. For two reasons, it is better to report the reaction ratio in terms of a linear logarithmic scale: first, the linear logarithmic scale has the same behavior with deviations of the numerator and denominator, which means that this ratio is most affected by the variation of the denominator (especially when the denominator is small), but the logarithm of this ratio is equally affected by changes in numerator and denominator. Second, the distribution of the reaction ratio is usually skewed, but the distribution of the reaction ratio in logarithmic form is usually normal. Therefore, the reaction ratio will be given as logarithmic (2), as follows (Hedges et al., 1999):

$$
L=\ln R=\ln \left(\frac{\overline{X E}}{X C}\right)
$$

The best way to compare different studies is to use the mean of their effects. However, in estimating the magnitude of the impact of different trials, there are differences in accuracy (standard error). Therefore, data must be weighted before meta-analysis, so that studies with a higher test accuracy have a higher weight. This increases the accuracy of the estimated effect. The mean effect size was estimated (3) as follows (Cohn and Becker, 2003):

$$
\overline{\ln R}=\frac{\sum_{i=1}^{n}(\ln R i \times W i)}{\sum_{i=1}^{n} W i}
$$


where $i$ is the study number, $w$ is the replication number in each trial, and $\ln R_{i}$ is the effect size of the trait from the $\mathrm{i}^{\text {th }}$ observation. The confidence interval for the average log response ratio was calculated (Hedges et al., 1999), and for ease of interpretation of the results, back-transformation was performed on the results of effect size analysis, and they were reported as the percentage change in the trait relative to the control $[(\mathrm{R}-1) \times 100]$. The heterogeneity test was performed among the effect sizes of environments using a chi-squared $\left(Q_{\mathrm{T}}\right)$ test (Rosenberg et al., 2004). The group heterogeneity $\left(Q_{\mathrm{B}}\right)$ and within-group heterogeneity $\left(Q_{\mathrm{W}}\right)$ were estimated, and a random-effects model was applied to determine heterogeneity in different groups (Lipsey and Wilson, 2001). Statistical analyses were carried out using the SAS and Excel 2016 software packages.

\section{Results}

\subsection{General environmental impact on sugar beet performance}

The general environmental impact on sugar beet performance is presented as boxplots in which the mean, the median and the variation of the data for each region are shown (Figure 3). Fifty percent of the values are shown as the box, with another $15 \%$ in the whiskers and the extreme 10\% as symbols (Hoffmann et al., 2009). As shown in Figure 3, yield and quality of sugar beet varied dramatically under different environments. For example, variation in root yield was from 8.3 to $140.3 \mathrm{t} \mathrm{ha}^{-1}$ across all environments. Averaged across all genotypes, the relative difference between minimum and maximum values was $20.8 \%$ for sugar content and $22.9 \mathrm{t} \mathrm{ha}^{-1}$ for sugar yield. Since the sugar yield is the product of root yield and sugar content, the higher sugar yield in Kermanshah was due to the high root yield in that environment; a high level of sugar content did not compensate for reduction in root yield. Mean white sugar yield ranged from 0.4 to $22.2 \mathrm{t} \mathrm{ha}^{-1}$ among environments, with Mashhad having the largest variation. Mean sugar yield, and as a consequence white sugar yield, was lower in Isfahan and Shiraz compared with other environments (Figure 3). However, the difference in impurities was much lower compared with root yield and sugar 
yield. Potassium did not show large differences among environments, but for $\mathrm{Na}$ and amino-N high extreme values occurred in Isfahan and Mashhad, and in Isfahan and Karaj, respectively (Figure 3 ). For the sugar extraction coefficient, low mean values occurred for Isfahan and slightly higher means in Kerman and Kermanshah. Very low variation was found for molasses sugar, from $1.16 \%$ to 7.19\%, with Shiraz and Kermanshah having the highest (3.97\%) and lowest $(2.23 \%)$ rate respectively (Figure 3 ).

\subsection{Meta-analysis}

Among the studied environments, Khoy had a positive effect on root yield, sugar content, sugar yield as well as white sugar yield. As can be seen in Figure 4, a negative growth was observed for the above-mentioned traits in Shiraz. In Shiraz, fields were contaminated with rhizomania and cyst nematode, and the contamination rate has increased in recent years. One reason for the higher root performance in Khoy may be the lower night temperature, which leads to less respiration and higher sugar accumulation (Figure 1). This trend was reversed for $\mathrm{Na}$ content, and Shiraz was replaced by Meshginshahr for $\mathrm{K}$ content. The Oroumieh environment had a negative impact on $\mathrm{N}$ accumulation, with the Kerman agro-climate yielding a higher $\mathrm{N}$ accumulation in root storage. Khoy had a positive impact on the sugar extraction coefficient in contrast with Moghan, Isfahan and Shiraz. As expected, the Khoy environment had a negative impact on molasses sugar accumulation, whilst Shiraz and Meshginshahr had a positive impact on $\mathrm{Na}$ and $\mathrm{K}$ as well as molasses sugar.

In Figure 4, positive and negative values (\%) illustrate an increase and decrease respectively. When the $95 \%$ confidence intervals did not overlap with zero, environment effects were considered significant [11-12].

The heterogeneity test of $Q_{\mathrm{T}}$ was highly significant for most of the traits except sugar content, $\mathrm{K}$, and sugar extraction coefficient (Table 2). In addition, the magnitude of the mean difference changed significantly among most of the traits except sugar content, $\mathrm{K}$, amino- $\mathrm{N}$, sugar extraction coefficient, and molasses sugar, illustrating the importance of the environmental effect on sugar 
A meta-analysis of genotype $\times$ environment interaction on sugar beet performance 229
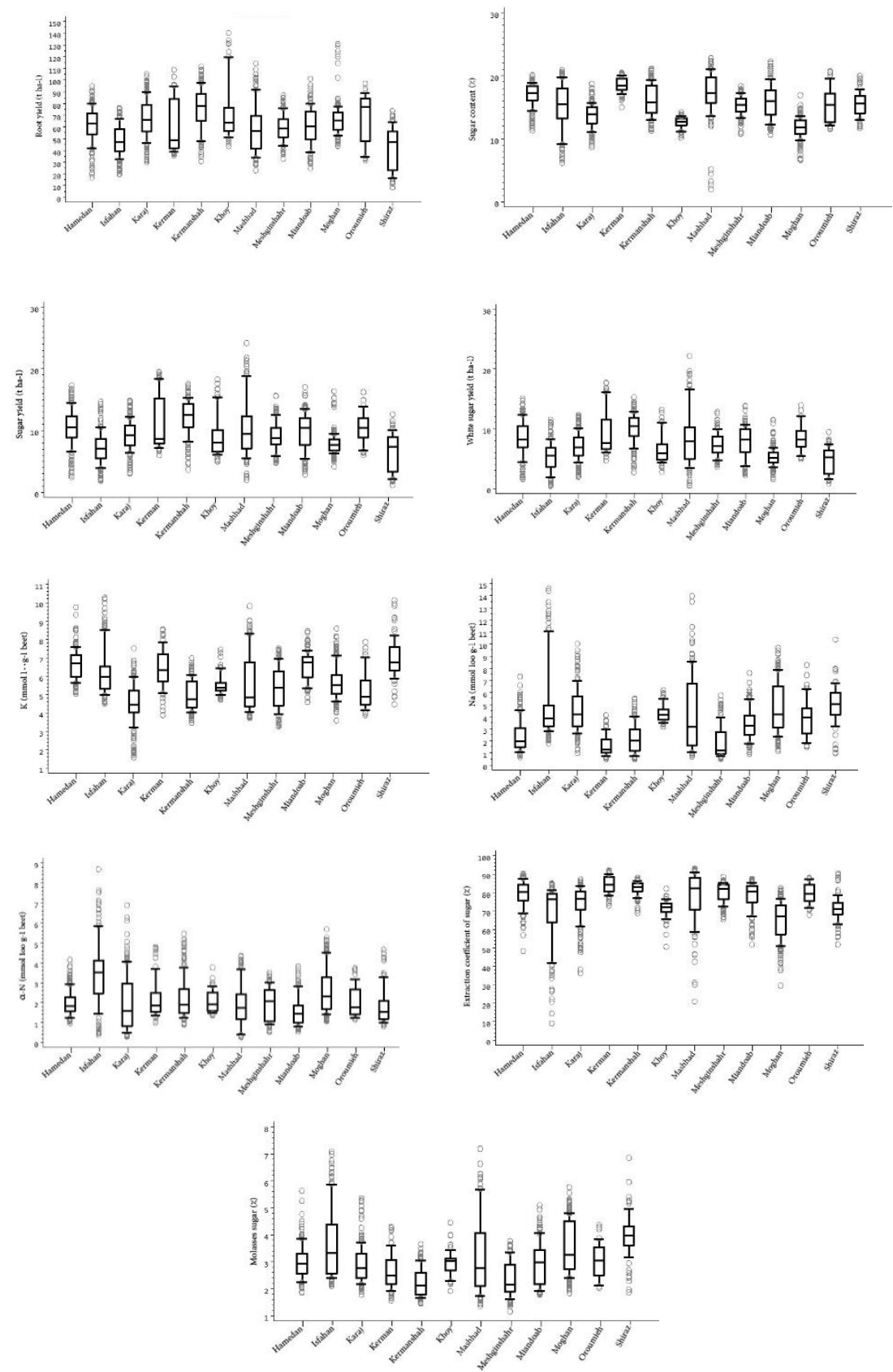

Figure 3. Mean and variation of quantitative and qualitative parameters of sugar beet genotypes in different regions from 2003 to 2018 

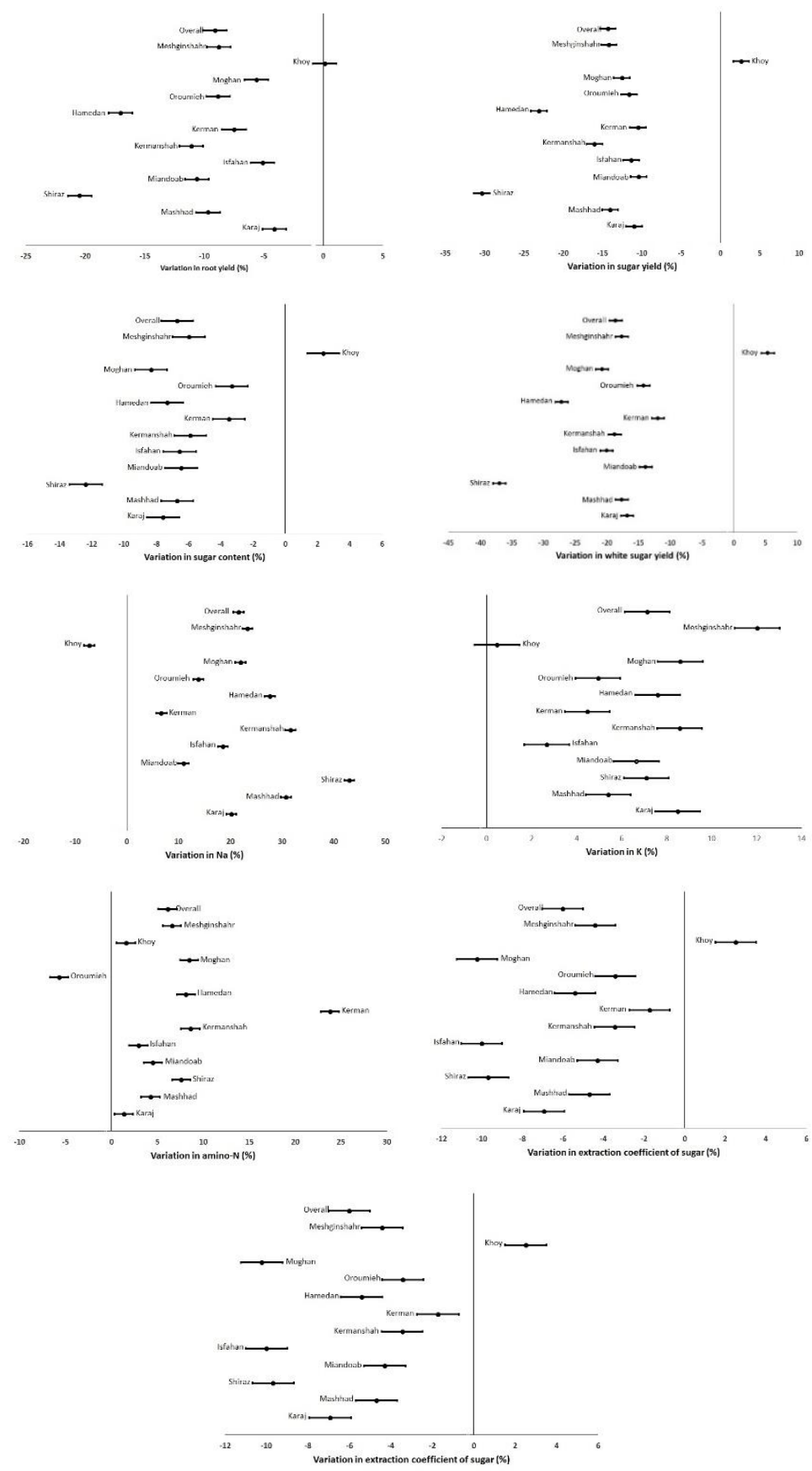

Figure 4. Effect of different environments on quantitative and qualitative parameters of sugar beet genotypes. Error bars are 95\% confidence intervals 
beet quantity and quality. Among impurity components, the highest $Q_{\mathrm{w}}$ was obtained for $\mathrm{Na}$.

Table 2. Total heterogeneity $\left(Q_{\mathrm{T}}\right)$, heterogeneity within $\left(Q_{\mathrm{w}}\right)$ and between $\left(Q_{\mathrm{B}}\right)$ groups among 1590 observations in different studies

\begin{tabular}{lccc}
\hline Groups & $Q_{\mathrm{T}}$ & $Q_{\mathrm{w}}$ & $Q_{\mathrm{B}}$ \\
\hline Root yield & $318.69^{* *}$ & $298.03^{* *}$ & $20.65^{* *}$ \\
Sugar yield & $453.18^{* *}$ & $416.12^{* *}$ & $37.06^{* *}$ \\
White sugar yield & $713.64^{* *}$ & $658.45^{* *}$ & $55.19^{* *}$ \\
Sugar content & 73.67 & 68.99 & $4.68^{* *}$ \\
$\mathrm{Na}$ & $723.44^{* *}$ & $674.37^{* *}$ & $49.06^{* *}$ \\
$\mathrm{~K}$ & 107.24 & 103.10 & 4.14 \\
Amino-N & $601.96^{* *}$ & $586.91^{* *}$ & 15.05 \\
Alkalinity & $713^{* *}$ & $684.56^{* *}$ & $28.43^{* *}$ \\
White sugar content & $238.43^{* *}$ & $216.60^{* *}$ & $21.82^{* *}$ \\
Sugar extraction coefficient & 91.02 & 83.59 & 7.42 \\
Molasses sugar & $196.22^{* *}$ & $183.78^{* *}$ & 12.44 \\
\hline **Significant at 0.01 probability level & &
\end{tabular}

\section{Discussion}

The meta-analysis of statistical analyses requires a large collection of statistical results from various studies in order to integrate its findings. To our knowledge, this is the first time that a meta-analysis of different environment effects on sugar beet performance has been reported for Iran.

Many researchers believe that performance is a good measure of a genotype's success, since it effectively integrates the interactions of metabolic processes and environmental effects into these processes, in other words, representing a synthesis of all processes. However, performance as a selection criterion is not the only empirical assessment of the combination of past events, and does not provide information about metabolic processes that increase the benefit. On the other hand, direct selection for performance may include restrictions such as limitation of genetic variation (Fasahat et al., 2014; Fasahat et al., 2020). In this study, a wide range in root yield was present for the given environments. In previous studies, it has been shown that the climate has a strong influence on sugar beet growth, yield, and quality (Kenter et al., 2006; Hoffmann et al., 2009; 
Fasahat et al., 2020). For example, in a study by Hoffmann et al. (2009), nine sugar beet genotypes were evaluated in 52 environments across European countries for root yield and quality. The results illustrated that the environment accounted for about $80 \%$ of the total variance for all parameters. A positive influence on high root yield achievement marked the Khoy environment as favorable for sugar beet growing. A low night temperature, especially in summer, may contribute to lower respiration and higher sugar accumulation in the root (Fasahat et al., 2018). Considering that the grouping of experimental stations in terms of sugar yield is similar to that for root yield, it seems that the sugar yield is more affected by root yield than sugar content. For example, the Oroumieh station has a very high root yield and an average sugar content, and was placed in the first group for the sugar yield trait. In addition, the Karaj, Khoy, and Meshginshahr environments were approximately similar in terms of sugar yield and were placed in the same group. Despite the fact that the average sugar content was high in Shiraz, it achieved the lowest sugar yield $\left(6.67 \mathrm{t} \mathrm{ha}^{-1}\right)$ and was placed in the third group. This indicates the importance of root yield in determining the sugar yield. In sugar beet, sugar yield is influenced by several factors such as year and place of production. Freckleton et al. (1999) reported that mean temperature in April (early season), and mean temperature and rainfall in late July and August (mid-season) have a significant effect on yield formation in sugar beet (King and Tarkalson, 2017).

Among the studied environments, the greatest negative effect of environment on sugar content was observed in Shiraz, followed by Moghan. Taleghani et al. (2000) reported that the trend of sugar content variation in Moghan region is different from other parts of the country, so that in most regions the process of sugar accumulation in the root is usually incremental from sowing to harvest, and depending on the environmental conditions, the slope of the line may vary partially but maintains its incremental status, while in Moghan, reduction in sugar content can be seen in early September to the beginning of October. As with other regions of the country, the trend of root weight increase is always upward, but its value is lower in the months of October and November. Low sugar content in 
Shiraz is due to the effect of a specific factor in this region; considering that the soil of the experimental fields at the Research Station of Zarghan, Shiraz, is contaminated with different levels of rhizomania, this point may be significant. Particularly, there have been reports of a decrease in the sugar content in sugar beets infected with rhizomania (De Biaggi et al., 2010). King and Tarkalson (2017) evaluated the link between climate variables and sugar beet sucrose content of sugar beet genotypes in southern Idaho and eastern Oregon in the period 1997-2014. They attributed a wide difference in sugar beet sucrose content to variation in grower production practices and seed genetics. However, mean sucrose content difference between locations in the studied years was largely attributed to climatic differences, and partially to the irrigation method. High levels of white sugar yield are due to low root impurities and, consequently, lower molasses and as a result higher levels of white sugar content. As shown in Figures 3 and 4, the average white sugar yield in different environments showed a wide range of variation.

Among insoluble non-sugar substances (impurities), $\mathrm{Na}, \mathrm{K}$ and amino- $\mathrm{N}$ have drawn attention in cultivar breeding programs. The amounts of $\mathrm{Na}, \mathrm{K}$ and amino$\mathrm{N}$ vary greatly over several selection generations, indicating that genes with an additive effect control these traits (Smith and Hecker, 1973). Furthermore, the interaction between impurity components, sugar content and root yield makes it extremely difficult to maximize performance as well as quality.

There are major differences among the studied environments under the climatic conditions of Iran in this study. A significant increase in $\mathrm{Na}$ concentration in rhizomania-contaminated fields was observed, so that $\mathrm{Na}$ content in Shiraz was twice the average $\mathrm{Na}$ concentration of the studied environments. Sodium concentration in Shiraz is relatively high compared with the average $\mathrm{Na}$ concentration in the cold and mountainous regions of Khoy, Miandoab, and Hamedan as well as the semi-arid region of Karaj. It can be stated that soil contamination with rhizomania increased $\mathrm{Na}$ concentration, as other researchers have reported (ITB, 2008). Hoffmann et al. (2009) reported a high environmental effect (94\%) for $\mathrm{Na}$ accumulation in sugar beet. Nitrogen 
concentration in sugar beet root is strongly affected by field management, including nitrogen fertilizer and irrigation. However, environmental stresses such as drought, salinity and high temperatures during the growing season increase its concentration. There are also reports that contamination with rhizomania causes a decrease in nitrogen intake (Asher, 1993; Heijbroek, 1988); in conditions of infection with the disease, the root system is shortened in the susceptible variety and hence nitrogen uptake will be reduced. In other studies, high contents of $\mathrm{K}$, $\mathrm{Na}$, amino-N and molasses sugar are attributed to the response of the beet to abiotic stress conditions (Bloch et al., 2006; Mack and Hoffmann, 2006).

Molasses sugar showed a different response pattern in contrast to other parameters; a rather similar mean value and small variation in the environments marked it as the most stable compound with respect to environmental conditions. Variation in molasses sugar percentage is a function of impurities and in general, like impurities, has a decreasing trend. Although the root yield of sugar beet genotypes is remarkable in Moghan, low sugar content, high molasses sugar, relatively high $\mathrm{Na}$, and high levels of amino- $\mathrm{N}$ in that environment caused a reduction in white sugar yield and the sugar extraction coefficient, which are the important quantitative and qualitative factors for the evaluation. In turn, although Hamedan and Mashhad had lower root yield than Moghan, due to their high sugar content and low amounts of $\mathrm{Na}, \mathrm{K}$, and molasses sugar they could produce high white sugar yields and sugar extraction coefficients. In Isfahan, in view of low root yield, low sugar content and high levels of $\mathrm{Na}$ and molasses sugar, the environment is evaluated as inappropriate for sugar beet production. Although Mashhad is in the third group in terms of root yield, due to the relatively high sugar content and very low amounts of $\mathrm{Na}, \mathrm{K}$, amino-N and molasses sugar it was identified as a favorable environment for sugar beet production. Overall, the meta-analysis results showed that, considering root yield, white sugar yield, sugar extraction coefficient, and sugar content, the climate conditions of Khoy made it the most favorable environment. Although high levels of the above-mentioned traits were obtained in the Kermanshah and Kerman environments, these environments showed a negative influence. Moghan, Shiraz, and Isfahan were 
evaluated as the most inappropriate environments. Kerman and Oroumieh were also evaluated as moderate environments.

\section{APPENDIX}

Number of experiments considered for this study in twelve regions within 15 years (2003-18)

\begin{tabular}{llcllc}
\hline No. & Region & $\begin{array}{c}\text { Number of } \\
\text { experiments }\end{array}$ & No. & Region & $\begin{array}{c}\text { Number of } \\
\text { experiments }\end{array}$ \\
\hline 1 & Karaj & 19 & 7 & Kerman & 9 \\
2 & Mashhad & 13 & 8 & Hamedan & 16 \\
3 & Shiraz & 9 & 9 & Oroumieh & 5 \\
4 & Miandoab & 14 & 10 & Moghan & 21 \\
5 & Isfahan & 13 & 11 & Khoy & 5 \\
6 & Kermanshah & 14 & 12 & Meshginshahr & 11 \\
\hline
\end{tabular}

\section{REFERENCES}

Asher M.C.J. (1993): Rhizomania. In Cooke D.A. and Scott R.K. (eds.), The sugar beet crop. Chapman \& Hall, London: 312-346.

Barker H.L., Holeski L.M., Lindroth R.L. (2019): Independent and interactive effects of plant genotype and environment on plant traits and insect herbivore performance: A meta-analysis with Salicaceae. Funct Ecol. 33(3): 422-435.

Bengtsson J., Ahnsrtom J., Weibull A. (2005): The effects of organic agriculture on biodiversity and abundance: a meta-analysis. J Appl Ecol. 42: 261-269.

Bloch D., Hoffmann C.M., Marlander B. (2006): Solute accumulation as cause for quality losses in sugar beet submitted to continuous and temporary drought stress. J Agron Crop Sci. 192: 17-24.

Cohn L.D., Becker B.J. (2003): How meta-analysis increases statistical power. Psychol Methods 8(3): 243.

De Biaggi M., Stevanato P., Trebbi D., Saccomani M., Biancardi E. (2010): Sugar beet resistance to rhizomania: State of the art and perspectives. Sugar Tech 12 (3-4): 238-242.

Fasahat P., Aghaeezadeh M., Jabbari L., Hemayati S.S., Townson P. (2018): Sucrose accumulation in sugar beet: from fodder beet selection to genomic selection. Sugar Tech 20(6): 635-644.

Fasahat P., Khayamim S., Soltani IJ., Darabi S., Pedram A., Hasanai M., Jalilian A., Babaei B. (2020): Stability Analysis of Genotype $\times$ Environment Interaction Effect on Sugar Yield in Sugar Beet Hybrids. Journal of Crop Breeding 11(32): 33-40.

Fasahat P., Muhammad K., Abdullah A., Rahman B.M.A., Siing N.M., Gauch J.H.G., Ratnam W. (2014): Genotype $\times$ environment assessment for grain 
quality traits in rice. Communications in Biometry and Crop Science 9(2): 71-82.

Freckleton R.P., Watkinson A.R., Webb D.J., Thomas T.H. (1999): Yield of sugar beet in relation to weather and nutrients. Agr Forest Meteorol. 93(1): 39-51.

Francois L.E., Grieve C.M., Maas E.V., Lesch S.M. (1994): Time of salt stress affects growth and yield components of irrigated wheat. Agron J. 86(1): 100-107.

Gurevitch J., Hedges L.V. (1999): Statistical issues in ecological Meta-Analysis. Ecology 80: 1142-1149.

Hedges LV (1992): Modeling publication selection effects in meta-analysis. Stat Sci. 246-255.

Hedges L.V., Gurevitch J., Curtis P.S. (1999): The meta-analysis of response ratios in experimental ecology. Ecology 80(4): 1150-1156.

Heijbroek W. (1988): Dissemination of rhizomania by soil, beet seeds and stable manure. Nethe J Plant Pathol 94(1): 9-15.

Hoffmann C.M., Huijbregts T., van Swaaij N., Jansen R. (2009): Impact of different environments in Europe on yield and quality of sugar beet genotypes. Europ J Agron. 30(1): 17-26.

Huang S., Zeng Y., Wu J., Shi Q., Pan X. (2013): Effect of crop residue retention on rice yield in China: A meta-analysis. Field Crop Res. 154: 188-194.

ITB (2008): Diagnostic d'automne des betteraves maladies. La Technique Betteravière n'899 4.

Kenter C., Hoffmann C.M., Marlander B. (2006): Effects of weather variables on sugar beet yield development (Beta vulgaris L.). European J Agron. 24(1): 62-69.

King B.A., Tarkalson D.D. (2017): Irrigated sugarbeet sucrose content in relation to growing season climatic conditions in the northwest US. Journal of Sugar Beet Research 54(1\&2): 60-74.

Linquist B.A., Liu L., van Kessel C., van Groenigen K.J. (2013): Enhanced efficiency nitrogen fertilizers for rice systems: Meta-analysis of yield and nitrogen uptake. Field Crop Res. 154: 246-254.

Lipsey M.W., Wilson D.B. (2001): Practical meta-analysis. SAGE publications, Inc.

Mack G., Hoffmann C.M. (2006): Organ-specific adaptation to low precipitation in solute concentration of sugar beet. Europ J Agron. 25: 270-279.

Owen F.V. (1945): Cytoplasmically inherited male-sterility in sugar beets. J Agr Res. 71: 423-440.

Research Performance Report of SBSI. (2018): Technical reports, Sugar Beet Seed Institute publication, Karaj, Alborz, pp. 13-17.

Rosenberg M.S., Garrett K.A., Su Z., Bowden R.L. (2004): Metaanalysis in plant pathology: synthesizing research results. Phytopathology 94: 1013-1017.

Soltani E., Soltani A. (2015): Meta-analysis of seed priming effects on seed germination, seedling emergence and crop yield: Iranian studies. Int J Plant Prod. 9(3): 413-432.

Taleghani D., Moharammzadeh M., Gohari J., Kashani A., Tohidloo Q., Chegini M.A. (2000): Study of correlation between reduction of sugar content and leaf re-growth of sugar beet in Moghan region. Sugar Beet 16(2): 13-30. 